\title{
Unusual cause of bilateral lower limb edema in a male with ADPKD
}

\begin{abstract}
A 53 year old male presented with vague pain and worsening swelling of both lower limbs since one week. Venous doppler study of lower limbs unmasked DVT involving bilateral saphenofemoral, superficial popliteal and popliteal veins with a high total plasma homocysteine of $29.76 \mathrm{umol} / \mathrm{L}$ (5.46-16.20umol/L. CT Venogram showed chronic thrombosis of the IVC and bilateral renal veins with acute thrombosis in bilateral common iliac, external/internal iliac, bilateral common femoral and superficial femoral veins. Colonoscopy showed multiple colonic diverticulae. 2-D ECHO showed myxomatous AML suggestive of mitral valve prolapsed (MVP).
\end{abstract}

Keywords: polycystic kidneys, deep vein thrombosis, homocysteine, colonic diverticulae, mitral valve prolapse
Volume 7 Issue I - 2019

\section{Anand Yuvaraj, Madhusudan Vijayan, Saravanan S, Milly Mathew, Georgi Abraham Department of Nephrology, Madras Medical Mission, India}

Correspondence: Georgi Abraham, MD, $\operatorname{FRCP}(\mathrm{L}), \operatorname{FRCP}(\mathrm{G})$, Department of Nephrology, Madras medical mission, Chennai, 4-a, Dr.JJ. Nagar, Mogappair, Chennai-600037, India, Tel -+919841710992, Email abraham_georg@@yahoo.com

Received: December 27, 2018 | Published: February 08, 2019

\section{Case history}

A 53 year old male vegetarian, not diabetic or hypertensive and did not have a history of cardiovascular, hepatic or kidney disease, presented to us with vague pain and worsening swelling of both lower limbs since 1 week. Physical examination was unremarkable except for bilateral tender pitting edema of feet, legs and thigh. Investigations showed $\mathrm{Hb} 116 \mathrm{~g} / \mathrm{L}, \mathrm{WBC}$ count $8.9 \times 10^{9} / \mathrm{L}$, platelet $301 \times 10^{9} / \mathrm{L}$, ESR $72 \mathrm{~mm} / \mathrm{hr}$, blood urea nitrogen $21 \mathrm{mmol} / \mathrm{L}$, serum creatinine $132 \mathrm{micromol} / \mathrm{L}$, Urine albumin nil. Saturation was $98 \%$ in room air. Chest X ray was unremarkable. Venous doppler study of lower limbs unmasked DVT involving bilateral saphenofemoral, superficial popliteal and popliteal veins with normal arterial doppler. Tc-99m lung perfusion was normal. LFT, fasting lipid profile, electrolytes and thyroid function were normal. HIV, HBsAg and anti HCV were negative. Protein $\mathrm{C}$, protein $\mathrm{S}$ activity, antithrombin III, factor $\mathrm{V}$ leiden mutation, APLA were unremarkable but a high total plasma homocysteine of $29.76 \mathrm{umol} / \mathrm{L}(5.46-16.20 \mathrm{umol} / \mathrm{L})$. B12 level was low $(188 \mathrm{pg} / \mathrm{ml})$ and he was given IM. methylcobalamin $1000 \mathrm{mcg}$ for 7 days. CT Venogram showed chronic thrombosis of the IVC and bilateral renal veins with acute thrombosis in bilateral common iliac, external/internal iliac, bilateral common femoral and superficial femoral veins (Figure 1).

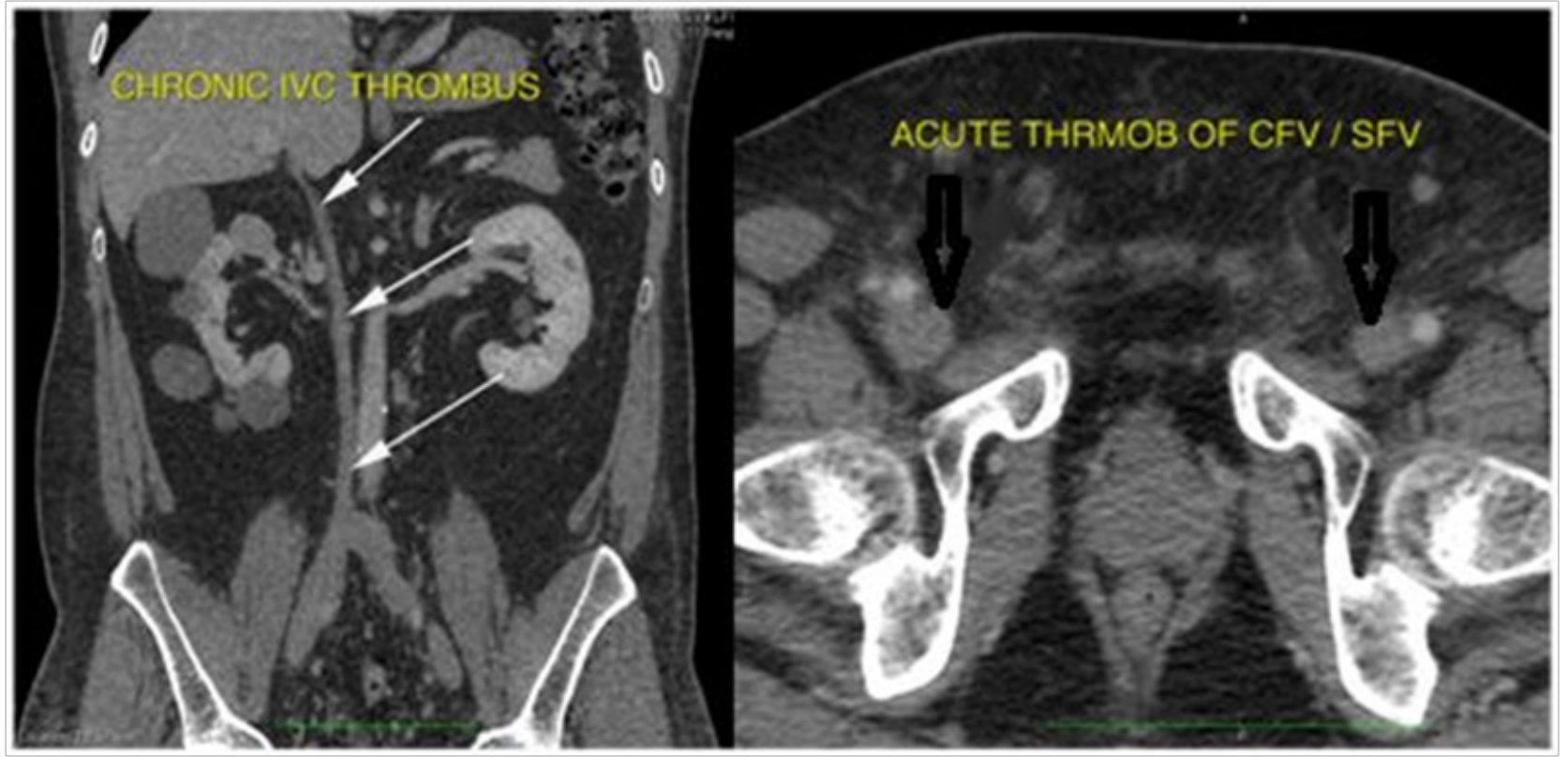

Figure I CT Venogram showed hypoplastic IVC as depicted by thinned out IVC with chronic thrombosis(white arrows) with acute thrombosis in bilateral common femoral/superficial femoral veins depicted by distended veins when compared to the arteries(black arrows).

CT Abdomen with contrast showed right kidney $10 \mathrm{X} 6.1 \mathrm{~cm}$ with $>10$ cysts, Left kidney 9.6 X5.1 cm with 3-4 cysts, the largest cyst on either side measuring about $6 \mathrm{~cm}$ (Figure 2). Tc-99m Isotope renogram scan revealed total GFR $65 \mathrm{ml} / \mathrm{min}$ (left kidney $52 \mathrm{ml} / \mathrm{min}$, right kidney $13 \mathrm{ml} / \mathrm{min})$ 


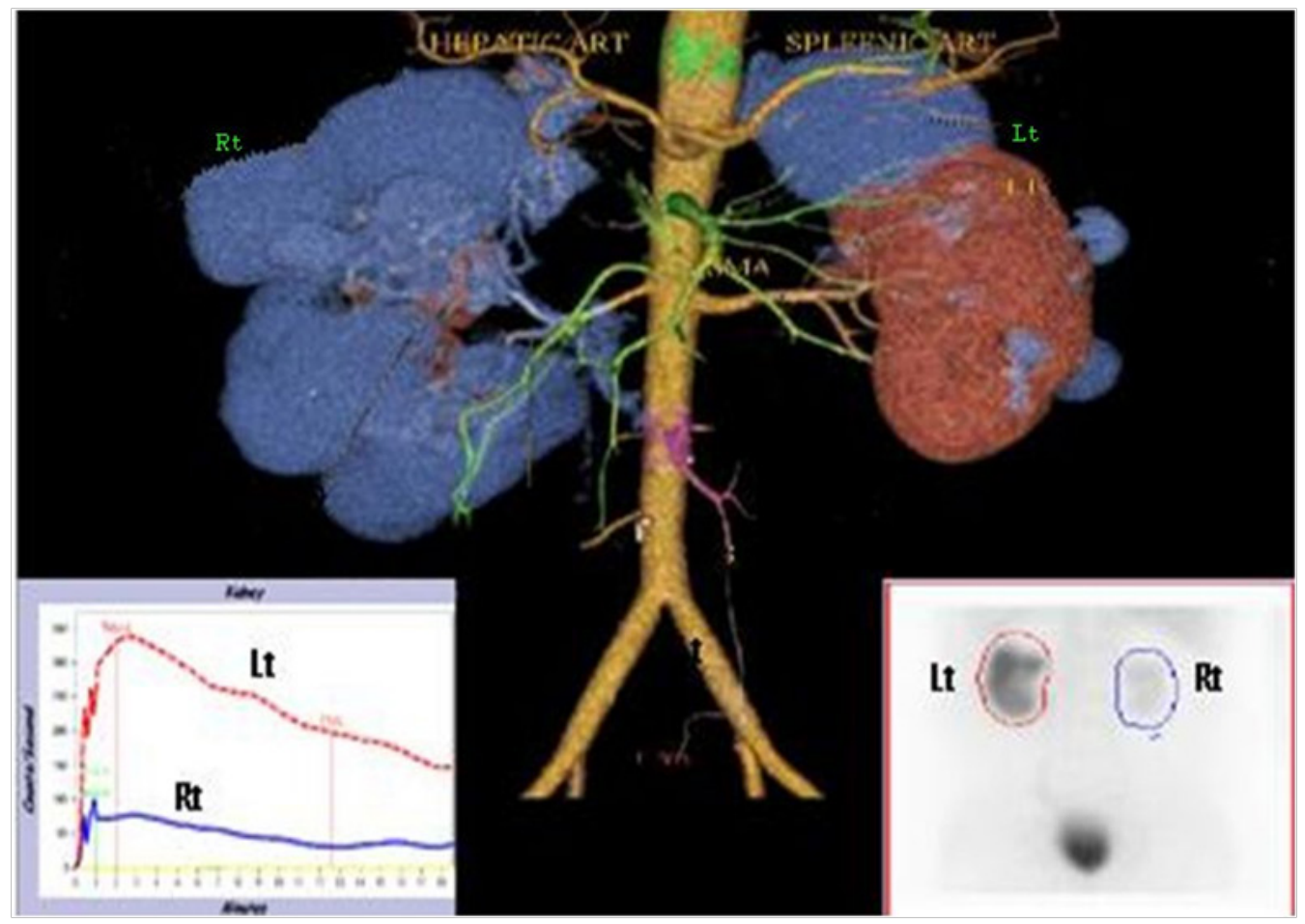

Figure 2 CT Abdomen with contrast shows Right kidney $10 \times 6.1 \mathrm{~cm}$ with $>10$ cysts, Left kidney $9.6 \times 5.1 \mathrm{~cm}$ with $3-4$ cysts, the largest cyst on either side measuring about $6 \mathrm{~cm}$ with Tc-99m Isotope renogram revealed total GFR $65 \mathrm{ml} / \mathrm{min}$ (left kidney $52 \mathrm{ml} / \mathrm{min}$, right kidney $13 \mathrm{ml} / \mathrm{min}$ ).

Prostate malignancy was ruled out. Plasma CEA and CA19-9 were normal, stool occult blood negative, upper GI endoscopy showed gastric ulcer with duodenal erosions with biopsy from lesions ruling out malignancy, colonoscopy showed multiple colonic diverticula (Figure 3).

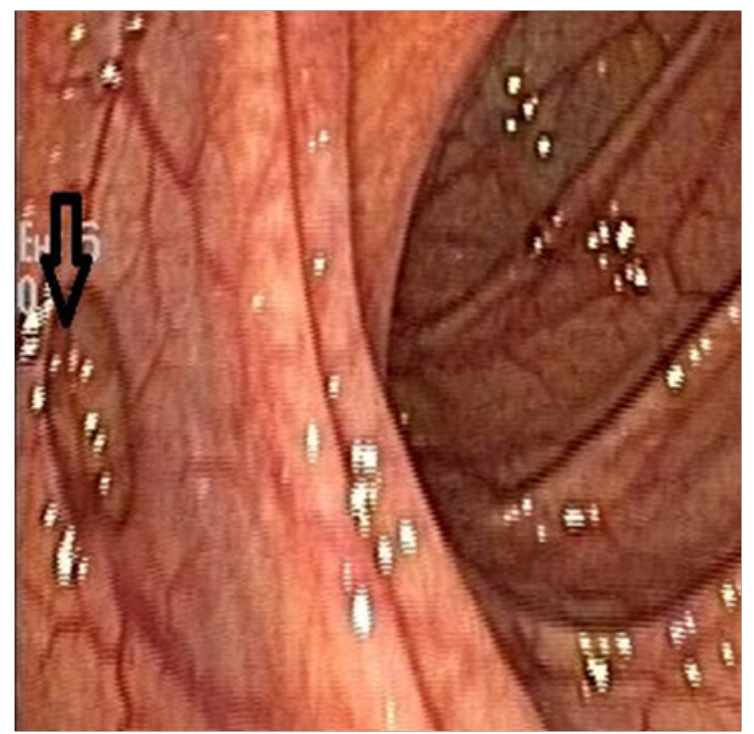

Figure 3 Coloscopy showing colonic diverticuli(arrow).

2-D ECHO showed good biventricular function, EF-62\%, type 1 diastolic dysfunction, myxomatous AML suggestive of mitral valve prolapse(MVP) (Figure 4).

He was treated with Inj. Enoxaparin $60 \mathrm{mg}$ s/c BID followed by oral warfarin to maintain the PTINR between 2 and 3. Patient also received additional $\mathrm{B} 6$ and folic acid for hyperhomocystinaemia.

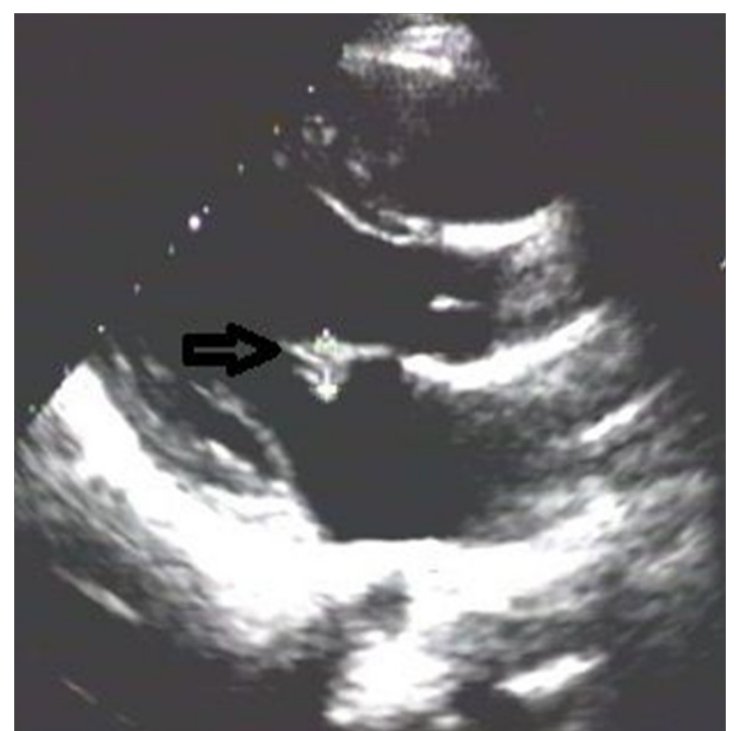

Figure 4 2-D ECHO showing myxomatous AML (arrow) suggestive of mitral valve prolapse(MVP).

\section{Discussion}

Venous thrombosis and hypercoagubility is a common complication of malignancy ${ }^{1}$ and hypoplasia of the IVC, described as an incidental finding, should be taken into account when otherwise unexplained DVT develops in young people. ${ }^{2}$ Hyperhomocysteinemia is a risk factor for recurrent venous thrombosis in patients between 20 and 70 years of age. ${ }^{3}$ Our patient had a hypoplastic IVC as depicted by thinned out IVC with mild to moderate hyperhomocystinaemia explaining the probable cause for venous thrombosis. However an extensive workup to detect malignancy was negative. 
ADPKD is associated with MVP in up to $25 \% .{ }^{4}$ There are rare case reports of thrombosis in the inferior vena cava (IVC) due to enlarged cysts in autosomal dominant polycystic kidney disease. ${ }^{5}$ Our patient showed number of cysts to meet the required criteria for $\mathrm{ADPKD}^{6}$, with Stage II CKD, MVP, multiple colonic diverticulae and IVC thrombosis, had no positive family history, with only elder brother having late onset minimal change disease. Genetic workup for ADPKD is done. Literature review did not show association of IVC hypoplasia with cystic kidney disease.

\section{Acknowledgments}

None

\section{Conflicts of interest}

Authors declare there is no conflict of interest.

\section{References}

1. Rickles FR, Edwards RL. Activation of blood coagulation in cancer: Trousseau's syndrome revisited. Blood. 1983;62(1):14-31.

2. Cei M, Cei F, Vitale J, et al. Hypoplasia of the inferior vena cava and deep vein Thrombosis. QJM. 2013;106:459-460.

3. Den HM, Blom HJ, Gerrits WBJ, et al. Is hyperhomocysteinaemia a risk factor for recurrent venous thrombosis? Lancet. 1995;345:882-885.

4. Nahm AM, Henriquez DE, Ritz E. Renal cystic disease (ADPKD and ARPKD). Nephrol Dial Transplant. 2002;17(2):311-314.

5. Maeda T, Uchida Y, Oyamada K, et al. Thrombosis in inferior vena cava due to enlarged renal cysts in autosomal dominant polycystic kidney disease. Intern Med. 2010;49(17):1891-1894.

6. Franck AB, Charles LE. Unified Ultrasonographic Diagnostic Criteria for Polycystic Kidney Disease. J Am Soc Nephrol. 2009;20(1):6-8. 